\title{
Notes on Male Rhytidectomy
}

\author{
M.R. Wexler* \\ Section of Plastic Surgery, University of Michigan Medical Center, \\ Ann Arbor, Michigan 48104, USA
}

Summary. Measurements of 100 preauricular hairline distances were done, and a normal average was established. The joined male rhytidectomy and the "frontal alternating fusiform" excisions are described.

Key words: Rhytidectomy - Preauricular hairline - Joined incision Frontal fusiform excision.

\section{Introduction}

Only a few articles are dedicated to male rhytidectomy $[1,3,4]$ a procedure which is in increasing demand. The major difference between male and female rhytidectomy lies in the preauricular incision since it is necessary in the male to leave a non hairy area in front of the ear to avoid too close approximation of the hairline to the ear. Measurements to establish the "normal" hairline were done on 100 patients. Some of the techniques used in 10 male rhytidectomies are described.

\section{The Normal Preauricular Hairline in the Male}

100 normal males in the age span between $20-45$ were included in this study. To obtain the average normal preauricular hairline five points were chosen (Fig. 1):

1) the vertical distance between the ear and the hairline, at the anterior junction of the helix (average $4.25 \mathrm{~mm}$ ),

2) the horizontal distance between the ear and the hairline at the anterior junction of the helix (average $7.50 \mathrm{~mm}$ );

* Present address: M.R. Wexler, M.D., Department of Plastic Surgery, Hadassah University Hospita1, P.O. Box 499, Jerusalem, Israel 


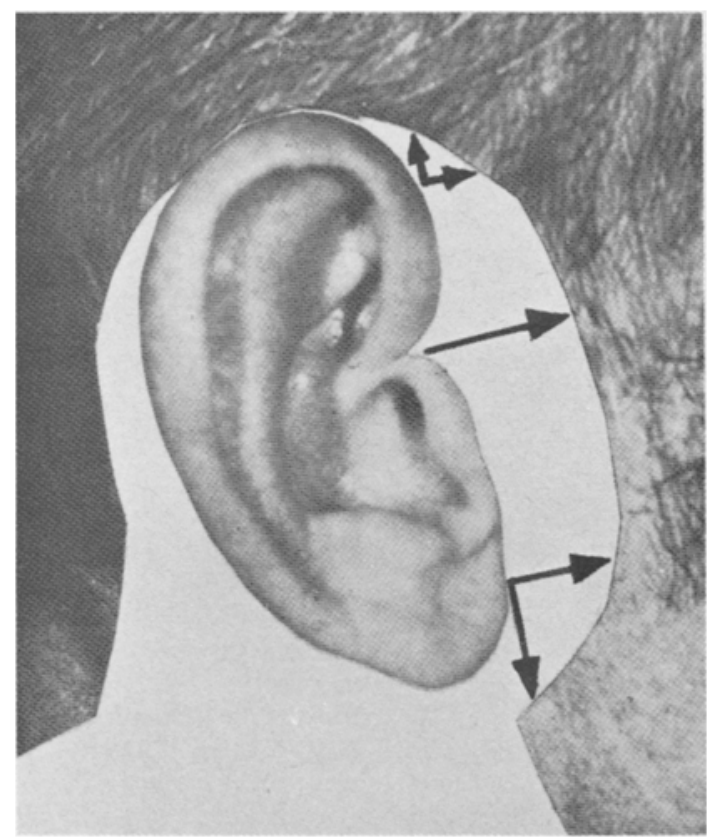

Fig. 1. Scheme of the five points measured from the ear to the preauricular hairline: 1 Anterior junction of helix vertical to hairline (average $4.25 \mathrm{~mm}$ ). 2 Anterior junction of helix horizontal to hairline (average $7.5 \mathrm{~mm}$ ). 3 Junction of crus-helicis-tragus to hairline (average $16.5 \mathrm{~mm}$ ). 4 Insertion of lobule-horizontal to hairline (average $12 \mathrm{~mm}$ ). 5 Insertion of lobule-vertical to hairline (average $12.5 \mathrm{~mm}$ )

3) the horizontal distance between the junction of the crus helicis to tragus and the hairline (average $16.5 \mathrm{~mm}$ );

4) the horizontal distance between the insertion of the lobule and hairline (average $12 \mathrm{~mm}$ );

5) the vertical distance between the insertion of the lobule and the hairline (average $12.5 \mathrm{~mm}$ ).

It should be mentioned that these are the figures for the local population in Israel composed of Jews and Arabs and different figures are to be expected in populations of different origins.

\section{The Joined Incision}

In 3 cases out of 10 male rhytidectomies (Cases No. 1 and 2) an incision joining the lower blepharoplasty incision and the preauricular incision was carried out (Fig. 2d). 4-0 clear nylon was used for plication of the parotid fascia and for subcuticular tension sutures. Undermining and elevation of the redundant skin over the malar region was needed to a very limited amount, as excision of full thickness skin and plication resulted in a good "lift" in this region. 

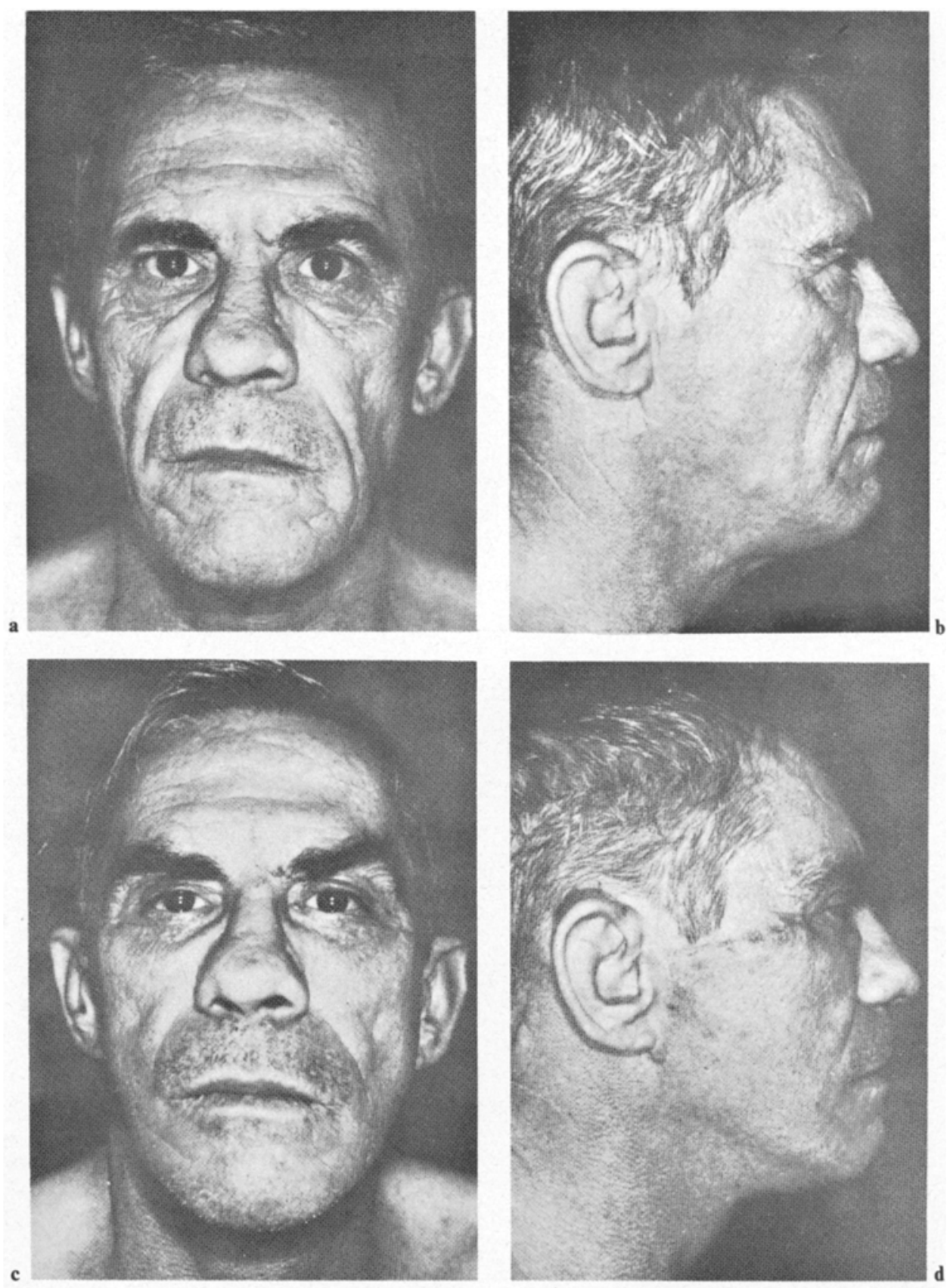

Fig. 2a-d. a Frontal view of case No.1 prior to face lift and blepharoplasty. The excess cheek skin was excised along a line joining the lower blepharoplasty and preauricular incision ends b Lateral view of case 1 preoperatively

c Frontal view 1 month postoperatively

d Lateral view 1 month postoperatively. The scar joining the lower blepharoplasty and preauricular incision is still evident 


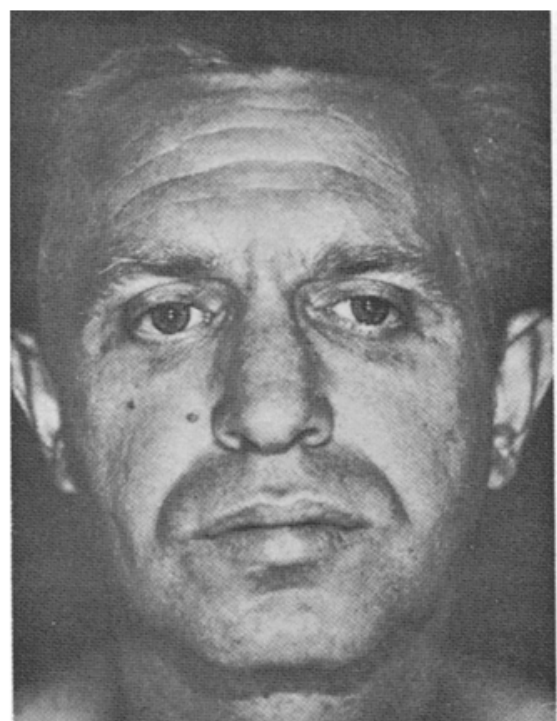

Fig. $3 \mathbf{a}$ and b. a Case No. 2 preoperatively.

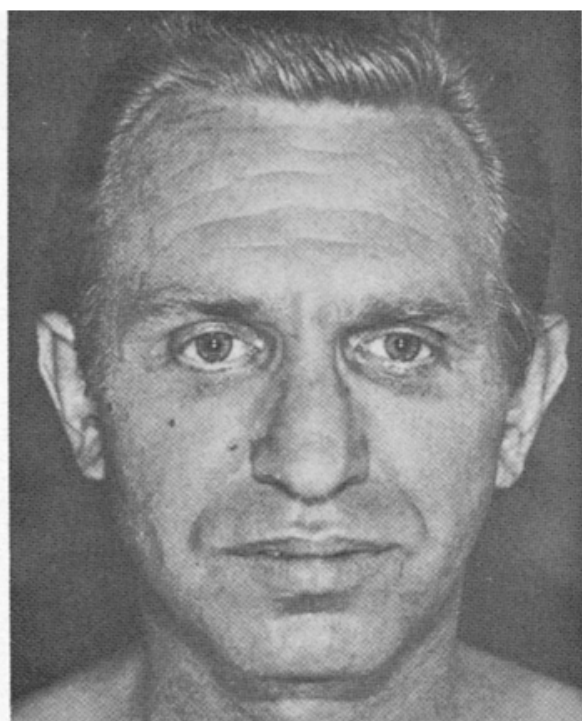

b Case No. 2. Three months postoperatively

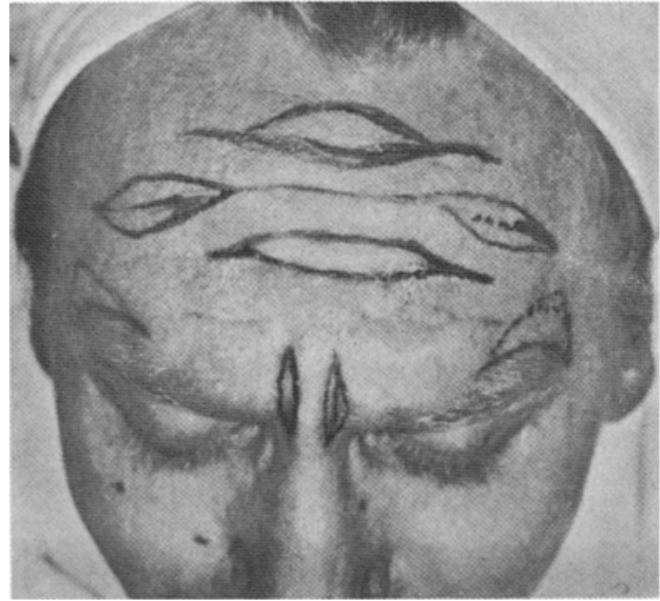

Fig. 4. Operative view Case No. 2 with the frontal alternating fusiform excision, outlined with methylene blue

\section{Frontal Rhytidectomy}

Frontal rhytidectomy was done (Case No. 2) through the horizontal forehead wrinkle lines in alternating fusiform excisions. The receding hairline is avoided and the scalp hair is actually brought down towards the eyebrows. 


\section{Discussion}

Conway [2] had 5\% of male rhytidectomies among 488 face lifts. He did not describe the male rhytidectomy technique.

The necessity to preserve the beard pattern was emphasized by Baker and Gordon [1]. In their words: "The cheek flap must not advance into the ear canal for it is most cifficult, if not impossible to shave inside the external auditory canal". We should add that not only from the technical point of view (difficulties of shaving) but, from the pure-aesthetic point of view, hairy skin in close approximation to the ear is not desirable. Though Baker and Gordon recommended that "the incision runs anterior to the tragus at the junction of beard with the non hair bearing line - a natural line of demarcation" an incision along this line will leave too wide an area of non hairy skin in front of the ear, and in people who have narrow sideburns there may be no hairy skin in front of the ear following the face lift. We suggest that before surgery is begun the surgeon should pull the preauricular skin downward and forward simulating the postoperative "pull" and then should mark the above mentioned 5 points, connect them thus creating the future normal preauricular hairline, and incise along that line. Thus, part of the non hairy preauricular skin will be excised and part of it will be retained to preserve the normal pattern of preauricular hairline.

Rees [6] points out that up to 15 to 20 percent of people requesting rhytidectomy are males. He said: "The sideburns must be moved back in face lifting so that the beardless area (usually present between the posterior limit of the sideburn and the anterior helical and tragal margin) will be obliterated, moreover, the beard itself is moved posteriorly and superiorly so as to lie behind the lobule of the ear, virtually to the mastoid skin, necessitating shaving of this region after surgery." We do not agree to the preauricular obliteration of the normal sideburn. It is important also to retain hairless skin in front of the ear.

Gonzales-Ulloa, in his new approach [3] to rhytidectomy in men described the preauricular incision but did not describe at what distance the incision should be carried out.

Hamilton [4], in a recent article connected the horizontal incision with upper blepharoplasty incision. We prefer to connect it with the lower blepharoplasty incision, leaving a lateral bridge of untouched skin. We advocate the "joined incision" as this leaves the upper preauricular hairy skin untouched, thus avoiding any undeasired results like hair loss in front of the upper third of the ear in certain cases (it may raise the need to cut out a triangle of skin on the posterior-superior aspect of the preauricular hairline).

The frontal rhytidectomy advacated by Uchida [5] or the coronal forehead rhytidectomy are, to our view, applicable to the female rhytidectomy, and in the male a better cosmetic result is achieved using the forehead wrinkle.

Acknowledgment. The author thanks Dr. W.C. Grabb, Associate Professor of Plastic Surgery, University of Michigan Medical Center, Ann Arbor, Michigan, for his helpful remarks. 


\section{References}

1. Baker, T.J., Gordon, H.L.: Rhytidectomy in males. Plast reconstr. Surg. 44, 219 (1969)

2. Conway, H.: The surgical face lift rhytidectomy. Plast reconstr. Surg. 45, 124 (1970)

3. Gonzales-Ulloa, M.: Rhytidectomy in men. A new approach. Arch. Otolaryng. 96, 325 (1972)

4. Hamilton, J.M.: Rhytidectomy in the male. Plast. reconstr. Surg. 53, 629 (1974)

5. Uchida, J.I.: A method of frontal rhytidectomy. Plast. reconstr. Surg. 35, 218 (1965)

6. Rees, T.D., Wood-Smith, D.: Cosmetic facial surgery. p. 136. Philadelphia: W.B. Saunders Co. 1973

Received: August 30, 1976 